\title{
Traffic Calming \& Its Applicability in Sri Lanka
}

\section{K. S. Weerasekera}

\begin{abstract}
This paper examines the concept of traffic calming, tools and methods available for traffic calming process, its effectiveness in countries which traffic calming strategies are adopted, and looks at it's applicability in Sri Lanka especially in Colombo and its suburbs. Study observes the origin of traffic calming, how different traffic calming policies are practiced in some countries, tools and devices used for traffic calming, how it could be modified to suit different situations, and its adoptability in busy local towns mainly in Colombo.
\end{abstract}

This paper is supported by a comprehensive literature survey which examine and summarise previous studies conducted on different aspects of effectiveness of speed controlling tools used in traffic calming operations and the impacts (both positive and negative) on all road users and nearby residents. Although traffic calming may be a novel experience to Sri Lankan road engineers, it has been practiced in some countries quite extensively over a considerable period of time. The expected outcome of this paper is to make an awareness of traffic calming concept and process among traffic and highway engineers in the country and encourage them to practice traffic calming policies wherever applicable meaningfully in Colombo and its busy suburbs in Sri Lanka.

Keywords: Traffic Calming, Local Area Traffic Management, LATM

\section{Introduction}

'Traffic calming' is a term which is frequently used in discussions in urban traffic policy and traffic management strategy discussions in some developed countries, over the past couple of decades. More recently traffic calming term has been used to describe a much wider context of traffic management and restrain in cities world wide, including cities and towns in some developing countries as well. In short the term traffic calming include, any action or programme that reduces street traffic and slows down motor vehicles within residential and local areas to make the neighbourhoods safer and more people friendly (Russell and Pharaoh, 1990).

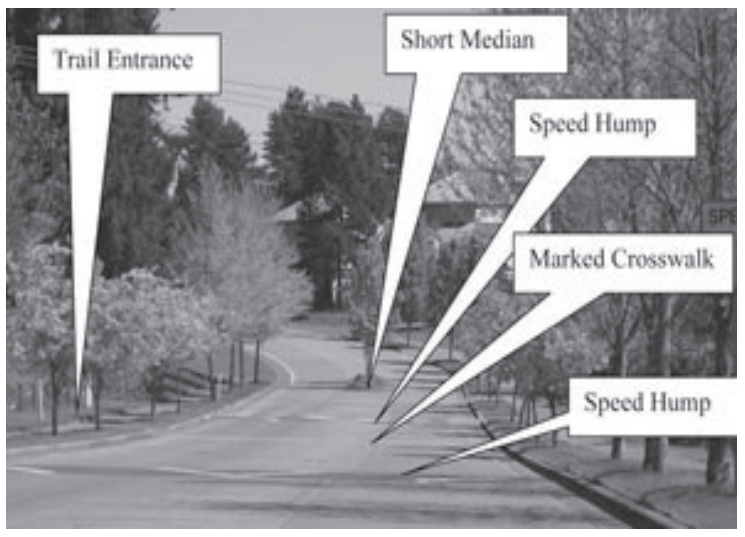

Figure 1 - Some Common Traffic Calming Tools (Source:www.americantrails.org/i/resourceimages/ptnyt. )
Figure 1 show some of the commonly used traffic calming tools used to slow down motor vehicles within residential and local areas to make the neighbourhoods safer and more people friendly.

Although numerous definitions of traffic calming are found in literature, all these definitions mostly play around with different words, but basically what they mean is the same. Traffic calming is "traffic control actions \& measures that offer to minimise the undesirable impact of motor vehicles on local human activities". It is important to mention that by calming traffic the accessibility and mobility should not be significantly reduce for the residents, commercial community, workers or visitors to the area. Traffic calming should not be misunderstood as lessening of traffic in an area, but it is a control measure to calm down traffic by reducing the average speeds of traffic, impose road discipline, and improve the safety of all road users.

Eng. (Prof.) K. S. Weerasekera, BSc Eng (Moratuwa), MEngSc (UNSW), PhD (UNSW), FIE (Sri Lanka), CEng, IntPE(SL), MIE (Aust), CPEng, MIHT (UK), MASCE,

Professor in Civil Engineering, Department of Civil Engineering, The Open University of Sri Lanka. 


\section{Origin and History of Traffic Calming}

Looking into the origin and history of traffic calming; as per Hass-Klau (1990), the traffic calming term is roughly a translation of German word verkehrsberuhigung. It is an amalgamation made up from verkehr (traffic) and beruhigung (comfort, calm or ease of mind). According to Brindle (1991) the word verkehrsberuhigung first appeared in German technical literature in mid 1970 's to describe speed control measures that were being applied to local streets. At the time there was a growing concern in Europe to improve the liveability of urban streets by reducing the adverse impacts of motor vehicles.

Traffic calming evolved in Europe from early 1970s in different countries under different terminologies. In Netherlands the "woonerf" or 'shared zone' concept was practiced in old established residential areas well before 1960s. The main objective of the Dutch woonerf principle was to design streets which made some kind of co-existence possible between pedestrian activities and vehicle usage on residential streets (Hass-Klau, 1990).

In Germany speed limiting practices such as Tempo 30, 40, 50 (limiting speeds in residential and other sensitive areas) was practiced in late 70's (Schleicher-Jester, 1989). Sweden adopted "TRAFIKPLAN 77" in 1977. Later in 1977, SCAFT guidelines were tried in some European countries.

In the mean time TRRL in UK was involve in developing and experimenting with road humps for controlling speeds in residential roads and speed bumps for parking areas (Hodge 1992; Bulpitt 1995). These experiments led to the development of famous Watt's profile in 1973 (Watts, 1973). Down under in Australia the concepts of Local Area Traffic Management (LATM) schemes were developed in calming or pacifying traffic in local and residential areas (Ashton 1981; Brindle 1991).

\section{Objectives and Levels of Traffic Calming}

The objectives of traffic calming can be basically categorised in to four areas; enhance safety, space for movement, pollution reduction, and aesthetics. They can be summarised as follows.

\subsection{Enhance Safety}

Enhance safety through eliminating potential accident hazards. It is utmost important to control/guide vehicle movements to protect human life, prevent injuries to all road users and avoid any property damage.

\subsection{Share Urban Space with People}

When vast expanses of road carriageways are established as space lost to human activity, particularly when space is not adequately utilised by vehicles, then through concept of coexistence (or shared paths) give back some road space to the pedestrians and cyclists while ensuring their safety.

\subsection{Reduce Pollution and Noise (Minimise Environmental Impacts)}

The impacts on environment through vehicular emissions, smoke, noise and, vibration has to be minimised. The importance of protection of the environment is well understood all over the world. Hence through traffic calming actions, impact on environment should be minimised.

\subsection{Aesthetics and Achieving Harmony between Pedestrians, Vehicles \& Residents}

It is generally accepted that motor vehicles are intrusive and dominating elements, particularly in residential environments. Hence it is important to have a safe co-existence and harmony between pedestrians, vehicles \& residents.

If we consider a real road network, we have following three dominant elements, (i) arterial roads, (ii) local roads, and (iii) collector roads as shown in Figure 2.

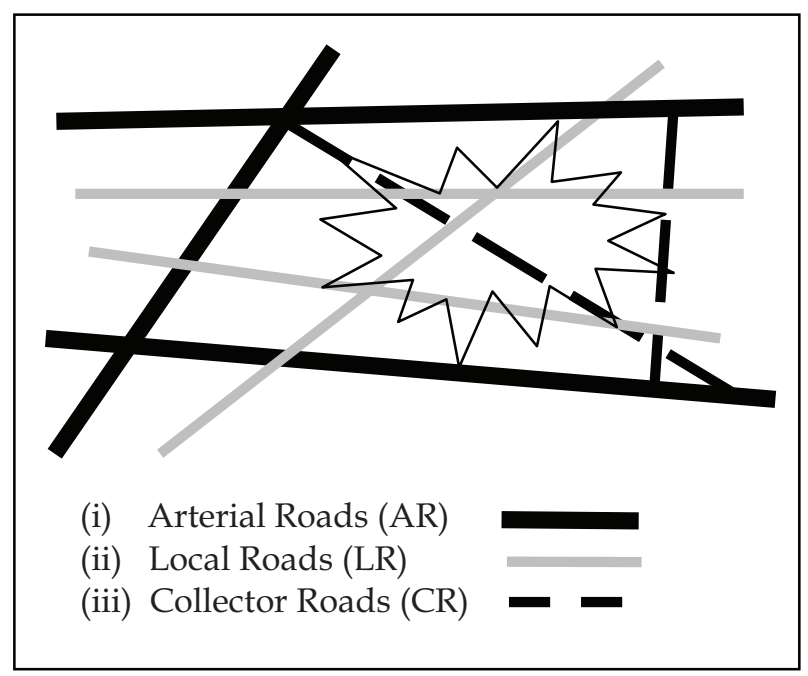

Figure 2 - Road Hierarchy in a Road Network 
The principal function of a collector road is to distribute traffic between the arterial roads and local roads. It 'collects' traffic from a catchment of local roads and then branching off it and connects up to a local crossing road or arterial road.

Local crossing roads are those roads which fulfil a need to directly cross a local traffic area because in one dimension at-least, the area is too large to be reasonably circumnavigated by intrasuburban traffic.

As per Brindle (1991) there are three levels of traffic calming that could be adopted.

Level 1 Traffic Calming - Actions to restrain traffic speed and lessen traffic impacts at the local level, where traffic volumes, levels of service and network capacity are not an issue.

In Level 1 traffic calming (at local level), few local roads with problems are selected and treat them.

Level 2 Traffic Calming - Actions to restrain traffic speed and lessen traffic impacts at the corridor (intermediate) level, where traffic volumes, levels of service and network capacity are an issue.

In Level 2 traffic calming (at intermediate level), select a residential area and treat as a unit.

Level 3 Traffic Calming - Actions at the macrolevel, to lessen traffic levels and impacts city-wide.

In Level 3 traffic calming (at Macro level), select a large area including arterial roads and treat the complete system.

\section{General Information}

In the post-war scenario it is seen that Sri Lankan traffic police is making a desperate attempt to discipline local traffic, and put into right course the local road users; both motorists and pedestrians. It is encouraging to see that Sri Lankan traffic police is working hard through various regulating schemes such as education campaigns, intensive roadside offender detection exercises, and monitoring programmes attempting to bring the law and order in highway usage. While enforcing is conducted it is also important to take steps to regularise both motorists, and pedestrians through correct policies.

While a broad concept of traffic calming is covered in this paper, it is important that we adopt our national standards depending on local demands and expectations to suit local conditions.

By traffic calming basically what's being carried out from traffic engineering point of view are as follows:

- Manage vehicular speeds to desirable levels

- Improve safety of both pedestrians and drivers

- Change of traffic flows

- Control noise levels

- Control environmental pollution (smoke, dust, harmful emissions)

- Travel time changes (increase / decrease)

- Local resident's privacy

- Road geometry changes

- Community attitudes (residents \& drivers)

- Passenger comfort

\section{Why Traffic Calming in Sri Lanka?}

It can be seen that on top of all safety awareness campaigns sphere-headed by Sri Lanka Traffic Police with other relevant road agencies, the road fatalities and grievous injuries in Sri Lankan roads are on the rise (Table 1). By looking at the total accident numbers indicated at the bottom row of Table 1, one may get the impression that accidents are reducing over the years; but according to traffic police, these numbers indicated in Table 1, reflect much lower figures than the actual numbers. The low values are due to roadside settlements arriving by affected parties without informing police with the help of insurance companies. Hence many of these minor category accidents are not getting recorded in police books. But the ground reality is that, Sri Lankan road accidents are on the rise. In this regard to somewhat it's welcoming news that Sri Lanka Traffic Police with the Defence Ministry approval has taken steps to install 100 roadside closed circuit TV cameras (CCTV) at crucial locations in Colombo for traffic monitoring purposes. To implement this island wide will be a very costly affair. 
Table 1 - The Annual Accident Statistics

\begin{tabular}{|c|c|c|c|c|c|}
\hline & 2004 & 2005 & 2006 & 2007 & 2008 \\
\hline Fatal & 2116 & 2141 & 2065 & 2176 & 2157 \\
\hline Grievous & 4560 & 4968 & 4710 & 5036 & 4963 \\
\hline Non grievous & 13918 & 14376 & 11866 & 12042 & 11437 \\
\hline Damage only & 32864 & 21686 & 14698 & 13204 & 11863 \\
\hline Total & 53458 & 43171 & 33339 & 32458 & 30420 \\
\hline
\end{tabular}

(Source: Sri Lanka Traffic Police, 2009)

By observing high level of driver indiscipline on local roads, and also police detection records of driver faults commonly found among our drivers over last few years it can be seen that majority of police detections are related to speeding, violation of road rules and unruly behaviour by three-wheeler drivers etc. (Table 2). All these high figures justify the importance and urgency to calm our traffic on roads. Hence it shows the importance of calming our traffic for better safety and improved road standards.

Table 2 - Police Detections from 2004 to 2008

\begin{tabular}{|l|r|r|r|r|r|}
\hline & $\mathbf{2 0 0 4}$ & $\mathbf{2 0 0 5}$ & $\mathbf{2 0 0 6}$ & $\mathbf{2 0 0 7}$ & $\mathbf{2 0 0 8}$ \\
\hline High Speeding & 113543 & 136846 & 125261 & 153388 & 151702 \\
\hline $\begin{array}{l}\text { Un Road - } \\
\text { worthy } \\
\text { vehicles }\end{array}$ & 1729 & 1591 & 2319 & 1735 & 1417 \\
\hline $\begin{array}{l}\text { Driving under } \\
\text { the Influence } \\
\text { of } \\
\text { Alcohol/Drugs }\end{array}$ & 10526 & 12826 & 11418 & 163083 & 189133 \\
\hline $\begin{array}{l}\text { Loading } \\
\text { Passengers } \\
\text { away from } \\
\text { Bus Halts }\end{array}$ & 27029 & 25296 & 25199 & 27181 & 21413 \\
\hline $\begin{array}{l}\text { Offences } \\
\text { committed by } \\
\text { Three-Wheeler } \\
\text { Drivers }\end{array}$ & 300470 & 322383 & 266238 & 279320 & 255710 \\
\hline $\begin{array}{l}\text { Offences } \\
\text { related to } \\
\text { violation of } \\
\text { Road Rules }\end{array}$ & 315959 & 338108 & 324727 & 372224 & 354399 \\
\hline $\begin{array}{l}\text { Failing to stop } \\
\text { at Pedestrian } \\
\text { Crossing }\end{array}$ & 38242 & 30629 & 198199 & 19762 & 7933 \\
\hline $\begin{array}{l}\text { Violation of } \\
\text { other Road } \\
\text { Rules }\end{array}$ & 884169 & 678083 & 715682 & 803745 & 720726 \\
\hline Total & $\mathbf{1 6 9 1 6 6 7}$ & $\mathbf{1 5 4 5 7 6 2}$ & $\mathbf{1 6 6 9 0 4 3}$ & $\mathbf{1 8 2 0 4 3 8}$ & $\mathbf{1 7 0 2 4 3 3}$ \\
\hline
\end{tabular}

(Source: Sri Lanka Traffic Police, 2009)

\section{Findings of Previous Studies}

An extensive literature survey was conducted to study on speed reducing tools used for traffic calming purposes in various countries and their conclusions are summarised below. Previous studies have identified twelve different impacts resulting from traffic calming tools as indicated in sub-sections 6.1 to 6.12. Findings of these studies will be very helpful in developing appropriate traffic calming schemes for different situations.

\subsection{Vehicle Speeds}

Next paragraph indicates the general conclusions arrived as an accumulation of studies conducted and published by following research publications regarding the impact on vehicle speeds due to traffic calming devices [Watts, 1973 (UK), Sumner and Baguley, 1978 (UK), Jarvis, 1978 (Aust), Ashton, 1981 (Aust), Kassem and Al-Nassari, 1982 (Saudi Arabia), Daff and Siggins, 1982 (Aust), Mehta, 1984 (Aus), Taylor and Rutherford, 1986 (Aus), Gennaoui and Smith, 1987 (Aus), Gorman et al., 1989 (USA), Broadbend and Salmon, 1991 (UK), Bicknell, 1993 (UK), Lines, 1993 (USA), Tan and Ward, 1994 (Aus), Macdonald, 1995 (UK), Weerasekera, 2009 (SL)].

It could be concluded from studies listed above that speed reductions by physical speed control devices used in traffic calming show that speeds near these devices can be controlled by varying parameters such as the type of device, the profile of the device, the spacing in between devices, the types of vehicles riding over the devices etc. All of these studies have contributed to the common conclusion that physical speed control devices are capable of effectively reducing the average speeds and percentile speeds near them. The spacing between the devices was seen as an important criterion. Increases in the spacing between devices resulted in higher average speeds and higher maximum inter-device speeds. The speed reduction at the devices depended on the severity of forced changes of trajectory of the vehicles. 


\subsection{Safety of Drivers and Pedestrians}

Next paragraph indicates the general conclusions arrived as an accumulation of studies conducted and published by following research publications on safety of drives and pedestrians [Sumner et al., 1978 (UK), Sumner and Baguley, 1978 (UK), Jarvis, 1980 (Aus), Mehta, 1984 (Aus), Gorman et al., 1989 (USA), Parker, 1989 (UK), Hodge, 1992 (UK), Evans, 1994 (UK), Bulpitt, 1995 (UK), Weerasekera, 1998 (Aus), Weerasekera, 1999 (SL)]

Supported by an extensive literature survey of 'before' and 'after' studies, it has clearly shown greater percentage reductions in accidents, sometimes as high as $80 \%$ in road stretches with road humps. Based on observations made on large number of traffic calming schemes, it is now well accepted that speed control devices contribute greatly towards improving the safety of both pedestrians and drivers.

\subsection{Traffic Flow Changes}

Next paragraph indicates the general conclusions arrived as an accumulation of studies conducted and published by following research publications on traffic flow changes due to traffic calming schemes [Ashton, 1981 (Aus), McDonald and Jarvis, 1981 (Aus), Parker, 1989 (UK), Van den Dool and Fisher, 1989 (Aus), Chua and Fisher, 1991 (Aus), Lines, 1993 (USA), Macdonald, 1995 (UK)]

All of the above studies showed that, from 'before' and 'after' traffic counts, traffic volumes were reduced once speed control devices were installed. These reductions in traffic volumes were often significant, and depended on the degree of speed control measures applied. It is evident that when speed control devices are used in traffic calming schemes, some traffic is diverted to adjacent routes since these routes become comparatively more attractive for travel. Hence, when traffic calming schemes are planned, it is important to ensure that the peripheral roads and adjacent major roads have the ability to accommodate this diverted traffic without congestion.

\subsection{Geometry}

Next paragraph indicates the general conclusions arrived as an accumulation of studies conducted and published by following research publications on the geometry of traffic calming tools [Watts, 1973 (UK), Walsh, 1975 (USA), Jarvis, 1978 (Aus), Kassem and AlNassari, 1982 (Saudi Arabia), Hagan, 1985 (Aus), Taylor and Rutherford, 1986 (Aus), Kjemtrup, 1988 (Denmark), Fwa and Tan, 1992 (Singapore), Macdonald, 1995 (UK)].

The earliest studies of various geometrical designs of road humps were conducted by Watts (1973), and Walsh (1975). Watts observed that very small humps are not effective for altering the drivers of all types of vehicles. It was found that the greater the height of the hump, the more severe the effect; short humps of greater heights, however were not acceptable on safety grounds. There has been large number of experiments carried out in different countries relating to the use of speed control devices with varying profiles for achieving effective results at lower costs. Taylor and Rutherford (1986) studied the family of 'diagonal slow points' devices used by many municipalities for speed control on local streets. Vehicle speed profiles were measured

\section{$6.5 \quad$ Noise}

Next paragraph indicates the general conclusions arrived as an accumulation of studies conducted and published by following research publications on noise changes due to traffic calming tools [Sumner and Baguley, 1978 (UK), Sumner and Baguley, 1979 (UK), McDonald and Jarvis, 1981 (Aus), Taylor, 1983 (Aus), Dewar, 1984 (Aus), Mehta, 1984 (Aus), Smith, 1985 (Aus), Gennaoui and Smith, 1987 (Aus), Chua and Fisher, 1991 (Aus), Van Every and Holmes, 1992 (Aus)].

A number of 'before' and 'after' studies indicated that there was an overall reduction in noise levels where traffic calming measures had been implemented, mainly due to the reductions in traffic volumes and speeds (Sumner and Baguley, 1978, 1979). In these studies it was found that, near mid-block humps and raised platforms, there was an increase in noise levels due to the rattling of goods in heavy vehicles, sudden braking of vehicles, and the constant acceleration and deceleration of vehicles. It was noticed that traffic noise is a very locationspecific impact and that the results can sometimes be confusing due to factors such as short survey durations, sudden fluctuations in traffic flow, occasional loud vehicles, and noises generated locally. The durations of noise 
recordings should be increased to obtain more definite conclusions.

Chua and Fisher (1991) stated that a $3 \mathrm{~dB}(\mathrm{~A})$ change in noise level is accepted as being necessary for the population as a whole to notice a difference in the noise. However, the available data on traffic speed and volume reduction suggested that a noticeable difference of $3 \mathrm{~dB}(\mathrm{~A})$ occurred in situations which had reductions of volume by $50 \%$, or somewhat lesser reductions coupled with greater speed changes (Sumner and Baguley 1978, 1979; Mehta, 1984). More studies of noise changes around speed control devices with longer survey durations have been proposed.

\subsection{Community Attitudes}

Next few paragraphs in section 6.6 indicates the general conclusions arrived as an accumulation of studies conducted and published by following research publications regarding community attitudes towards traffic calming schemes and tools used for traffic calming [Daff and Siggins, 1982 (Aus), Gennaoui and Smith, 1987 (Aus), Van den Dool and Fisher, 1989 (Aus), Gorman et al., 1989 (USA), Chua and Fisher, 1991 (Aus)].

Community attitudes towards speed-reducing devices have been reviewed in the studies listed above. There seemed to be strong agreement with the assumption that residential streets are primarily for the residents and secondarily for traffic. The studies above, most of which were based on public opinion surveys, interviews and household questionnaire surveys, show that the majority of the residents are in favour of speedreducing schemes in residential areas. These surveys also showed that the majority of the residents and divers were in favour of physical speed control devices such as road humps, raised platforms and slow points but that there was always a group who opposed them. The issue of physical speed control devices as a speed control measure has proved to be a very polarising issue; either people liked them or disliked them.

These studies show that the majority of the public accepted the notion that physical speed control devices helped to reduce overall speeds and traffic volumes on the roads however, there were somewhat different opinions on the following issues:
- Safety near these devices

- Minor damage and increased wear and tear to vehicles

- Appearance of these devices and changes to streetscapes

- Pedestrian crossing difficulties

- Travel time differences

- Road-side parking

- Effects on nearby property values

- Access from driveways

- Shapes and sizes of the devices

The common public complaints about humps and raised platforms wee related to noise generation near these devices and passenger/driver discomfort. All of these studies showed a general acceptance of these devices by the majority of the community if properly utilised.

\subsection{Driver and Passenger Comfort}

Next two paragraphs in section 6.7 indicates the general conclusions arrived as an accumulation of studies conducted and published by following research publications regarding driver and passenger comfort [Watts, 1973 (UK), Sumner and Baguley, 1978 (UK), Jarvis, 1980 (Aus), Kassem and Al-Nassari, 1982 (Saudi Arabia), Kjemtrup, 1988 (Denmark), Jarvis and Giummarra, 1992 (Aus)].

Kjemtrup (1988) commented that the vertical acceleration to which a person is subjected in passing over a hump depends on (i) the geometric design of the hump, (ii) the vertical speed, (iii) the vehicle suspension system, (iv) the vehicle tyre pressure, and (v) the softness of the seat, etc.

Jarvis (1980) produced a series of plots indicating driver/passenger discomfort versus vehicle crossing speed for different types of vehicles, and for different profiles of speed control devices, which suited Australian conditions. Many discomfort level (of driver/passenger) studies have been followed in other countries as well.

\subsection{Effects on Different Types of Vehicles}

Next two paragraphs in section 6.8 indicates the general conclusions arrived as an accumulation of studies conducted and published by following research publications on the effects on different types of vehicles [Watts, 1973 (UK), 
Jarvis, 1980 (Aus), Kjemtrup, 1988 (Denmark), Jarvis and Giummarra, 1992 (Aus)].

Watts (1973) studied the effect of road humps on different types of vehicles at varying crossing speeds, by giving different discomfort ratings for vehicles. It concluded that with respect to speeds, larger goods vehicles were the most affected for the majority of the different hump profiles that were investigated. Later, the on-site tests carried by TRRL (Sumner \& Baguley, 1978 \& 1979) showed large reductions of heavy vehicles and also a significant reduction in the number of motor cycles on roads with hump installations. Similar results were observed from a Danish study (Kjemtrup, 1988) which measured the effect of humps (C-humps and Thumps with varying dimensions) on 3 different types of vehicles (normal cars, buses and long, articulated vehicles). This study proved that cars pass over these devices with much more ease than longer vehicles.

From the ARRB research on different profiles of raised platforms it was found that raised platforms with ramp lengths of 2 meter and heights of $100 \mathrm{~mm}$ produced acceptable crossing characteristics for buses at speeds up to 24 $\mathrm{km} / \mathrm{h}$ (Jarvis and Giummarra, 1992). It was concluded that raised platforms with this profile had a good balance between the requirements for control of passenger car speeds, and the need for bus occupant comfort (both driver and passengers).

\subsection{Travel Time}

Next two paragraphs in section 6.9 indicates the general conclusions arrived as an accumulation of studies conducted and published by following research publications on travel time [Sumner and Baguley, 1978 (UK), Sumner and Baguley, 1979 (UK), McDonald and Jarvis, 1981 (Aus), Daff and Siggins, 1982 (Aus), Metha, 1984 (Aus)].

All of the above studies indicated that there was a definite increase in travel time depending on the length of road for which traffic calming was done and the degree of measures applied. TRRL studies (Sumner \& Baguley, 1978 \& 1979) showed considerable increase in average travel times, in some cases as high as $90 \%$ (at a location with nine Watts profile humps within a stretch of 750 metres) where the speed control devices were severely applied. Daff and Siggins (1982) observed a smaller percentage in average travel times $30 \%$ on a $1.7 \mathrm{~km}$ road stretch with seven horizontal displacement slow points.

Mehta (1984) noted that in the evaluation of some residential area traffic calming schemes in Australia an average travel time increase of between 20 and 40 seconds compared to without traffic calming tools. This was due to traffic diversions to peripherals, that resulting from the control measures applied to the residential area.

\subsection{Emergency Response Times}

Next three paragraphs in section 6.10 indicates the general conclusions arrived as an accumulation of studies conducted and published by following research publications on movement of emergency vehicles and effect on their response times due to traffic calming schemes [Daff and Siggins, 1982 (Aus), Gorman et al., 1989 (USA), Evans, 1994 (UK), Bulpitt, 1995 (UK)].

Evans (1994) observed that from a study done in UK, the most worrying criticism had come from ambulance and fire services, which had obvious concerns about the cumulative effect on their response times.

In contrarily Gorman et al. (1989) in their evaluation study of road humps in Omaha in US pointed out that for emergency vehicles the road humps were not an issue as long as they were placed on collector and major roads. They suggested that if a road hump is to be installed on such a road, police and fire departments should be consulted before proceeding. However, they commented that the actual increase in response time because of a typical road hump is of the order of a few seconds and argued that it is not life-threatening in most cases.

All the above studies commonly concluded that the installation of physical speed control devices increases the response time of emergency vehicles, although there are conflicting views on the importance of this increase.

\subsection{Fuel Consumption}

Next two paragraphs in section 6.11 indicates the general conclusions arrived as an accumulation of studies conducted and published by following research publications on 
the effect on fuel consumption due to traffic calming schemes [Taylor and Anderson, 1982 (Aus), Moses, 1989 (UK/USA), Zito and Taylor, 1996 (Aus)].

From a series of field experiments using an instrumented car equipped with ARRB's fuel travel time data acquisition system with a GPS positioning system and a speed and travel-time monitoring system, Zito \& Taylor (1996) observed that a road stretch with a series of humps increased vehicle fuel consumption, whereas the introduction of mini-roundabouts decreased the overall fuel consumption. These results confirmed the earlier claims by Moses (1989) that road humps and undulations of road surfaces increase the overall fuel consumption of vehicles, sometimes by up to $20 \%$.

The increases in fuel consumption when driving over vertical displacement devices and slow points are attributed to the constant changing of gears and travel in low gear near and on the devices.

\subsection{Air Pollution from Vehicle Exhausts}

Next two paragraphs in section 6.12 indicates the general conclusions arrived as an accumulation of studies conducted and published by following research publications on air pollution from vehicle exhausts due to traffic calming schemes [Taylor and Anderson, 1982 (Aus), Van Every and Holmes, 1992 (Aus), Bulpitt, 1995 (UK)].

Van Every \& Holmes (1992), from a review of literature on the environmental and energy benefits of LATM, found substantial evidence of a deterioration of environmental conditions due to increases in air pollution as a result of increased acceleration and braking by drivers near physical speed control devices. They shared the view that the impact on air quality as a result of an LATM scheme is related to the changes in fuel consumption. In LATM schemes with mid-block speed control devices this is normally a positive change and the percentage increase in fuel consumption was found to depend on the degree of traffic calming measures applied.

Taylor \& Anderson (1982), by applying the MULATM model to some South Australian LATM schemes, came up with similar views. Bulpitt (1995), by analyzing some traffic calming schemes in the UK which involved road humps and raised platforms, made similar observations to Van Every and Holmes (1992), and stated that vehicle exhausts increase air pollution as vehicles speed up or slow down over the obstacle course.

\section{Summary}

Sections 2, 3 and 5 of this paper investigates the concept of traffic calming, its origin and history, the objectives at different levels of traffic calming, and reason out why its required in Sri Lanka. Through the studies conducted in different parts of the world listed in section 6.1 to 6.12 it was observed, the historical background, the effects of tools used for traffic calming, their impact on different aspects, and also how at different parts of the world speed management issues in residential, collector, and sub-arterial routes without/with high pedestrian involvements are addressed through traffic calming.

\section{Implementation of Traffic Calming Schemes}

After studying the importance of vehicle/pedestrian interaction and the measures adopted to improve this relationship in different countries it was observed that the implementation of strict speed control measures such as road humps and raised platforms is now becoming familiar to many municipalities that are trying to reduce the speeds in residential streets as well as sub-arterial roads with high traffic flows. Some authorities are now not hesitating to use these devices on busy arterial roads running through town centres (Hopper \& Cannon 1994; Creed \& Menzies 1996). Traffic calming tools such as; raised thresholds, raised platforms, curvilinear alignments and traffic circles are suitable devices for busy arterial roads.

Where the conventional speed reducing measures with slight modifications are used in roads with high traffic with a high degree of vehicle/pedestrian interaction it is important to have a thorough understanding of the behaviour of these devices and their impact on fundamental characteristics of traffic. This literature search has been directed towards achieving a complete understanding of the existing knowledge of the performance of commonly-used physical speed control devices. The present knowledge about the performance of these tools has been assessed. 
From the literature study it was noted that there are some commonly used traffic calming tools which are extensively used all over the world for traffic calming operations. They are listed below:

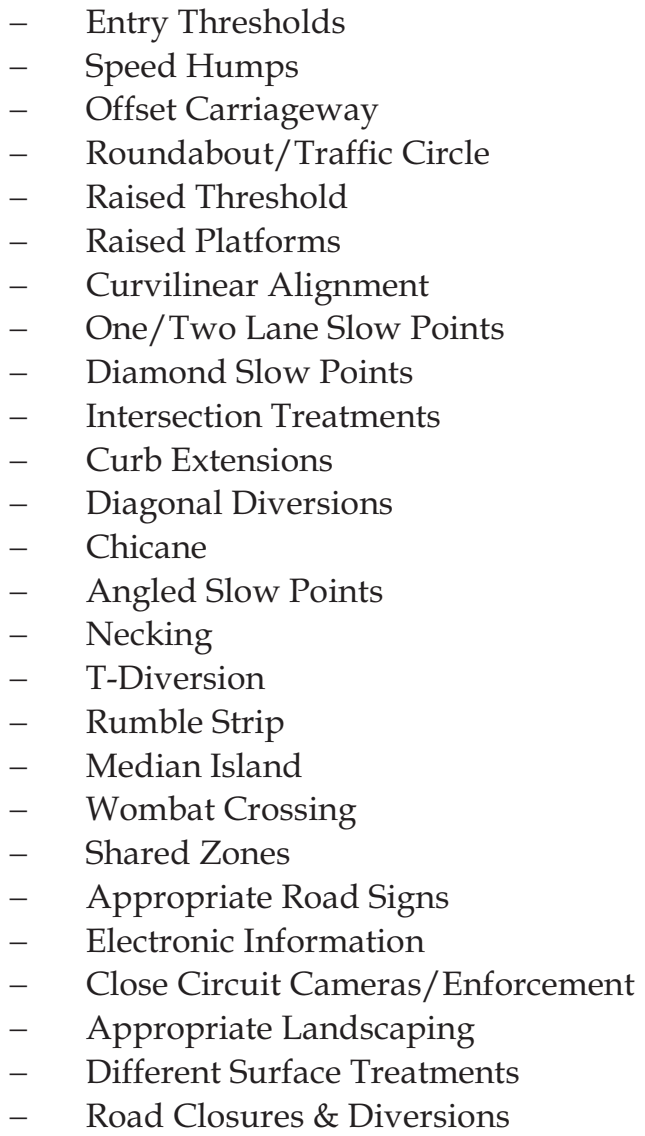

Some of the references indicated in this study offer comprehensive details of the traffic calming tools indicated above, with important dimensions of this different traffic calming tools, and also suggesting the suitable locations for their effective installations.

Figure 2 indicates an example of a simple typical traffic calming scheme that could be adopted in a residential area by using some of the above mentioned traffic calming tools. Similar type of traffic calming schemes (local/site specific) could be designed by traffic engineers with the agreement of all relevant stake holders.

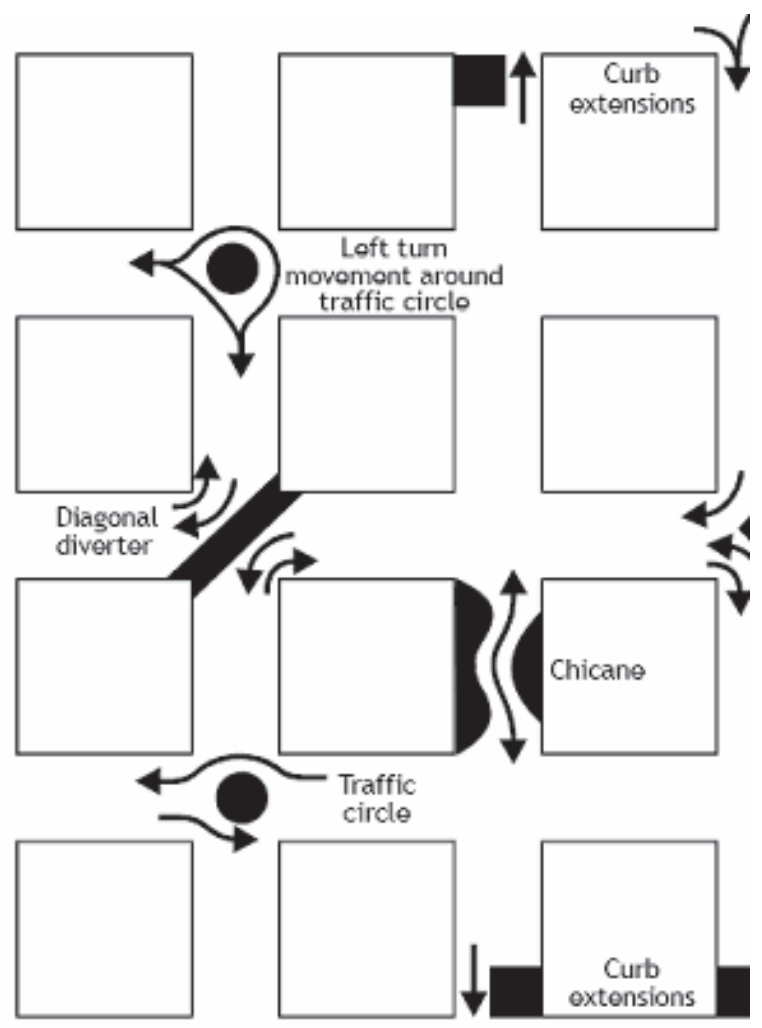

Figure 2 - Typical Traffic Calming Scheme

\section{Applicability in Sri Lanka}

Through this study it was attempted to demonstrate successful applicability of traffic calming for a sample of Colombo residential roads by studying a network of roads around Havelock Town and Thimbirigasyaya in Colombo 5.

Figure 3 indicates the locations of traffic calming tools that are proposed, and below indicates the list of tools that could be installed to implement the proposed Colombo traffic calming zone.

A - Roundabout/Traffic Circle

B - Chicane

C - Roundabout/Traffic Circle

D/E - Raised Platforms

F - Entry Threshold

G - Roundabout/Traffic Circle

$\mathrm{H} / \mathrm{I}$ - Raised Platforms

J - Raised Threshold

K - Roundabout/Traffic Circle

L - Traffic Signals

M - Roundabout/Traffic Circle

$\mathrm{N}$ - Traffic Signals

O - Speed Humps 


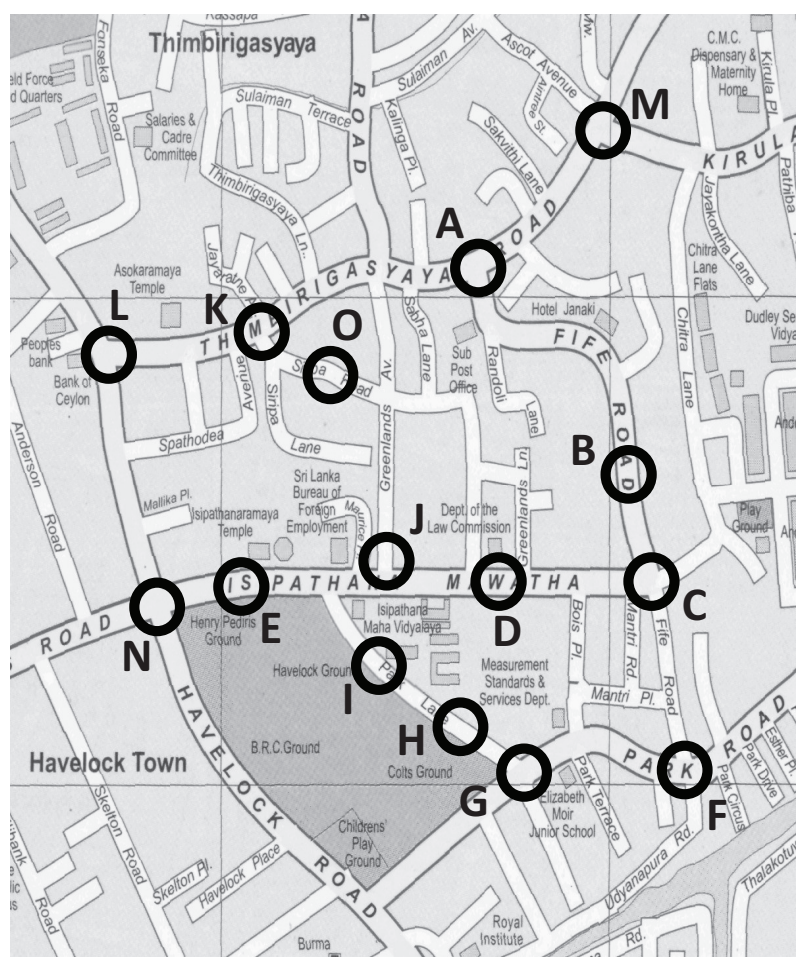

Figure 3 - Proposed Traffic Calming Scheme

\section{Conclusions}

It was observed from site investigations that the proposed Traffic calming scheme at Havelock Town and Thimbirigasyaya in Colombo 5 could be implemented with ease, since road widths are adequate for proposed traffic calming tools. But this may not the situation everywhere.

When traffic calming schemes are to be implemented under Sri Lankan context following are some of the difficulties that could be anticipated.

1. Since the local road users are not accustomed to traffic calming schemes a process of education may be necessary.

2. Available carriageway widths of our roads may be not sufficient for some of the traffic calming tool to be installed at some locations. Therefore some accepted tools used elsewhere may not be suitable for local conditions.

3. Research and further studies may be required in such cases. Research on space utilised, cost of structures and road user responses could be conducted to suit local conditions.
4. Unlike in some situations where local area traffic calming schemes have been successfully implemented in some developed countries, in Sri Lankan contest since the available road widths are narrow, solutions through introducing curvilinear alignment or carriageway narrowing will not be an appropriate solution.

5. The high costs involved in some installations may create difficulties to the relevant local road agencies.

6. If heavy traffic diversions occur on to local or residential roads residents may agitate.

7. Road authorities may have to face demands brought through pressure groups with vested interests \& political interferences that can take place.

It is important to remember that there is no ideal solution or type plan for any traffic calming scheme, but every scheme is different from one another and they are site specific and also should be acceptable to the stake holders who are the final beneficiaries.

\section{References}

1. Ashton, N. R., 'Achieving Lower Speeds in Residential Streets', First National Conference on Local Government Engineering, Adelaide, August 24-27, 1981.

2. Bicknell, D., 'Traffic Calming', Proceedings of the Institution of Civil Engineers', Vol. 98, Issue 1, March 1993.

3. Brindle, R. E., 'Traffic Calming in Australia: A Definition and Commentary', Journal of the Australian Road Research Board, Vol. 21, No. 02, June 1991, pp. 37-55.

4. Broadbend, K. and Salmon, A. M., 'An Experiment with Road Humps', Journal of Institution of Highways and Transportation, Vol. 38, No. 11, November 1991.

5. Bulpitt, M., 'Traffic Calming - Have we Given everyone the Hump or Is it just a Load of Chicanery?', Journal of the Institution of Highways and Transportation, Vol. 42, No. 12, December 1995.

6. Chua, C. S. and Fisher, A. J., 'Performance Measurements of Local Area Traffic Management: A Case Study', Journal of the Australian Road Research Board, Vol. 21, No. 2, June 1991. 
7. Creed, C. D. \& Menzies, B., 'Traffic Calming on Trunk Roads in East Cambridgeshire', Journal of the Institution of Highways and Transportation, East Midlands Special Issue, September 1996.

8. Daff, M. R. and Siggins, I. D. K., ‘On Road Trials of Some New Types of Slow Points', Proceedings of 11 th Australian Road Research Board Conference, Vol. 11, Pt. 4., 1982.

9. Dewar, W., 'The East Roseville Experiment: September 1983 - March 1984', Proceedings of the 3rd AITPM Forum, Sydney, 1984.

10. Evans, D., 'Traffic Calming: The First Five Years and the Oxfordshire Experience', Proceedings of the Institution of Civil Engineers - Municipal Engineer, Vol. 103, Issue 1, March 1994.

11. Fwa, T. F. and Tan, L. S., 'Geometric Characterization of Road Humps for SpeedControl Design', Journal of Transportation Engineering, Vol. 118, No. 4, July-August 1992.

12. Gennaoui, F. R. and Smith, F. A., 'Effectiveness of LATM Devices', $4^{\text {th }}$ National Local Government Engineering Conference, Perth, 17-21 August 1987.

13. Gorman, M. N., Moussavi, M. and McCoy, P. T., 'Evaluation of Speed Hump Program in the City of Omaha', ITE Journal, Institute of Transportation Engineers, Vol. 59, No. 6, June 1989.

14. Hagan, W. B. 'Physical Design Guidelines for Use in Residential Street Management', Third National Local Government Engineering Conference, Melbourne, 26-29, August 1985.

15. Hass-Klau, C, 'The Pedestrian City Traffic', Belhavan Press, London, 1990.

16. Hodge, A. R., 'A Review of the 20 mile/h Speed Zones: 1991', Traffic Engineering and Control, Vol. 33, No. 10, October 1992.

17. Hopper, K. and Cannon, R., 'Traffic Calming Hertfordshire's Town Centres', The Journal of the Institution of Highways and Transportation, Vol. 41, No. 10, October 1994.

18. Jarvis, J. R., 'A Survey of Traffic Speed Control Devices (Speed Humps) found in and around Melbourne', Australian Road Research Board, Internal Report, AIR 284-1, 1978.

19. Jarvis, J. R., 'The Off-road Testing of Road Humps for Use Under Australian Conditions', Proceedings of the 10 th Australian Road Research Board Conference, Vol. 10, Pt. 4., 1980.

20. Jarvis, J. R. and Giummarra, G., 'Humps for Use on Bus Routes', Road and Transport Research, Vol. 1, No. 4, December 1992.
21. Kassem, E. and Al-Nassar, Y., 'Dynamic Considerations of Speed Control Humps', Transport Research, Vol. 16B, No. 4, August 1982.

22. Kjemtrup, K., 'Speed Reducing Measures', Proceedings of the Australian Road Research Board, Vol. Pts 1-2, 1988.

23. Lines, C. J., 'Road Humps for the Control of Vehicle Speeds', Traffic Engineering \& Control, January 1993.

24. Macdonald, G., 'Quantifying Vehicular user Behaviour', Paper presented at the $7^{\text {th }}$ World Conference on Transport Research (WCTR), Sydney, 1995.

25. McDonald, P. E. and Jarvis, J. R, 'The use of Road Humps on Residential Streets in the Shire of Corio' ARRB International Report, AIR 335-2, 1981.

26. Mehta, A. 'Local Area Traffic Management: Lessons to date', Traffic Authority of NSW, November 1984.

27. Moses, P. J., 'Local Area Traffic Management in Europe and North America', 5 th National Local Government Engineering Conference, Sydney, 24-29, September 1989.

28. Parker, R. A, 'Road Humps, Do They Really Represent Good Value for Money?', Proceedings of European Transport and Planning, 17th Summer Annual Meeting, 11-15 September, PTRC Education and Research Services Ltd., 1989.

29. Russell, J. and Pharaoh, T., 'Speed Management and the Role of Traffic Calming in Road Safety', Research Paper No. 35, Department of Town and Country Planning, Heriot-Watt University, Edinburgh, 1990.

30. Schleicher-Jester, F., 'Tempo 30 in Towns Results of a German Experiment', Proceedings of European Transport and Planning, 17th Summer Annual Meeting, 11-15 September, PTRC Education and Research Services Ltd, 1989.

31. Smith, E. A., 'Traffic Noise and LATM', Australian Acoustical Society - 1985 Conference, 1985.

32. Sumner, R., and Baguley, C., 'Speed Control Humps in Norwich and Haringey', TRRL Supplementary Report SR 423, Transport Research Laboratory, Crowthorne, 1978.

33. Sumner, R., Burton, J. and Baguley, C., 'Speed Control Humps in Cuddesdon Way, Cowley, Oxford', TRRL Supplementary Report SR 350, Transport Research Laboratory, Crowthorne, 1978. 
34. Sumner, R. and Baguley, C., 'Speed Control Humps in Kensington and Glasgow', TRRL Supplementary Report SR 456, Transport Research Laboratory, Crowthorne, 1979.

35. Tan, H. W. and Ward, B., 'Vehicles through $90^{\circ}$ Bends', Proceedings of the Australian Road Research Board, Vol. 17, Pt. 5., 1994.

36. Taylor, M. A. P., 'Design Aids for Local Area Traffic Management', 2nd National Conference on Local Government Engineering, Brisbane, 19-22 September 1983.

37. Taylor, M. A. P. and Anderson, M., 'Modeling Pollution and Energy Use in Urban Road Networks', Proceedings of the Australian Road Research Board, Vol. 13, Pts. 7-9, 1982.

38. Taylor, M. A. P. and Rutherford, L. M. 'Speed Profiles at Slow Points on Residential Streets', Proceedings of the Australian Road Research Board, Vol. 13, Pts 7-9, 1986.

39. Van Den Dool, D. F. and Fisher, A. J., 'LATM Design Optimisation Can We Please Everyone?', $5^{\text {th }}$ National Local Government Engineering Conference, Sydney, 24-29, September 1989.

40. Van Every, B. and Holmes, M., 'Local Area Traffic Management: Effects on the Environment, Engineering and the Environment', Local Government Engineering Conference, Adelaide, 18-19 March, 1992, Department of Transport, Adelaide, 1992.

41. Walsh, L. B., 'A Study of Speed Bumps', Transportation Division, Dept. of Public Works, City of San Jose, California, 1975.

42. Watts, G. R. 'Road Humps for the Control of Vehicle Speeds', Transport and Road Research Laboratory 597, TRRL, UK, 1973

43. Weerasekera, K. S., 'Negative Effects of Midblock Speed Control Devices and their Importance in the Overall Impact of Traffic Calming on the Environment', Transportation Research an International Journal, Part D: Transport and Environment, Vol. 3D, No. 1, pp.41-50, Elsevier Science Ltd, USA, 1998.

44. Weerasekera, K. S., 'Some Disadvantages of Small Roundabouts or Traffic Rotaries' Proceedings of the International Conference on Environmental Challenges for the New Millennium, University of Jamia Milia Islamia, New Delhi, India, 25-29, November 1999.

45. Weerasekera, K. S., 'Achieving lower speeds in the Colombo Regional Centre, OUSL internal roads', Proceedings of the Annual Academic Sessions 2009 of the Open University of Sri Lanka, $15^{\text {th }} \& 16^{\text {th }}$ October 2009.
46. Zito, R. and Taylor, M. A. P. 'Speed Profiles and Vehicle Fuel Consumption at LATM Devices', Proceedings of Roads 96, Conference, Pt. 7, 1996.

47. www.americantrails.org/i/resourceimages/ptnyt 